\title{
Presentation and Communication of Financial Information for Investment Decision: Synthesis of the Literature
}

\author{
George Obeng \\ University of Education, Winneba \\ College of Technology Education Kumasi \\ Faculty of Business Education, Department of Accounting Education
}

\begin{abstract}
The focus of investment failure is seen as consequential to investors' irrational decision. Capital structure and classical theories, by literature, informed the investor in making their portfolio choices. Currently behavioural finance positslack of cognitive and psychological capacity of the investor in the use of complex information to make a rational investment decision. The rationality of information, how presented and communicated by management is not on the radar of experts and analysts. Literature is reviewed, addressing the presentation and communication of financial information in proactive market orientation for rational investment decision.The studyposits the relevance of communicating financial information in proactive market orientation as againstthe linearone-step modelapproach. Management should be responsible for any investment and corporate failure dependent on relevant financial information and how rationally communicated. Capital structure is a response of investors to management behaviour and not management choice.
\end{abstract}

Key words: Financial Information, Communication Strategy, Proactive Market Orientation

\section{I: INTRODUCTION}

Business capitalization results from investors' response to information communicated to them by the management of the firm acting as agents on behalf of the owners. The response which is the investment decision of the persons who have funds to invest determines the capital structure of the firm. Management from their own perspective may propose a structure and the investors in their understanding and interpretation of the information directs their decision as to the structure that befits the business firm. The choice making is rationalized and investors are to conform to set models and rules which theories have become fundamental to be internalized by investors in their portfolio ordering. Behavioural antecedents in investment decision can never always be rational to follow strict patterns according to behavioural finance. Business propositions are made to take advantage of opportunities to create wealth as manifested in the economic system and environment. People contribute financial resources required to advance the course of wealth creation of the business. The business has the responsibility to manage the resources made available to it judiciously to achieve and further its objectives and reward those advancing the financial resources. There should be a good balance between the self interest (Slain, 2002; Eaton, Eaton, Allen, 2005; Rutherford and Davison, 2007) of the parties; the reward to the capital providers and the profit for the business.Capital providers have forgone an alternate business proposition for the current investment and expect a better reward.

The business is competing with other businesses and needs to stay focus with current developments prevailing in the economic environment to be secured and be in business. This is the dichotomy of the business which needs to be properly managed to avoid investment and corporate failure. Failure of investors to secure their reward is a prerequisite to investment failure.Likewise if the business fails to generate enough revenue to meet its obligations with enough surpluses to stand the test of competitive world of technology it is equally a prerequisite to corporate failure. Management has to take every step available and reasonable to safeguard the interest of the capital providers and the assets of the business to make it attractive to current and potential investors. In the process managers generate a lot of information on the activities of the business. Management should put in place the right systems, standards and policies(Kumar and Goyal, 2016; Byrne, Jackson, Lee, 2013) that ensure rational (Lizieri (2009, p.

(C) 2019, IJSMS

Page 67 
150 in Byrne, Jackson, Lee, 2013) generation of information and how presented and communicated to all stakeholders for their investment decision. The classical models (Markowitz, 1952; Sharpe, 1964; Fama, 1971; Merton, 1972), construct the efficient frontier for rational investment decision.

There are other investment decision functions of several factors as; market characteristics, individual risk factors and accounting information that may also influence investment decision (Jangogo\&Mutswenje., 2014). The efficient frontier and other financial theories have been the accepted and driving forces that are mostly considered for investment decisions. Current developments is directing attention to the behavioural science in finance as a potential driver that plays significant role in investment decision (Livanas, 2008; Jangogo\&Mutswenje., 2014; Shefrin, 2000; Shleifer, 2001; Warneryl, 2001; Baberis\&Thaler, 2003; Byrneet'al, 2013). There may be different investors with different objectives, interest and utility, information needs and disposition. To restrict the possibility of traditional or classical and behavioural theories synchronizing as a process to arrive at rational investment decision is a fallacy. These different investors may have different information needs and levels from different sources that could affect the efficiency and outcome of the decision. The concept of bounded rationality suggests that individuals can only process a limited set of information available on the market (Islam Khan et'al, 2017). Limited human capacity hinders processing a broader set of information (Simon, 1957; Miller, 1957; Kahneman, 1973 in Islam Khan et'al, 2017). Therefore, instead of using all the available information, individuals typically reduce the amount of information used to a more manageable set (Shiller, 1989; Scharfstein and Stein, 1990; Coval and Moskowitz, 1999). Along the lines of this argument, institutional investors also confine their information sources to selective information. Kong and Kong (2015) find that institutional investors behave speculatively resulting in market inefficiency.

It is important to acknowledge and appreciate the need of relevant information, the reaction and behaviour of potential investors towards such information in their investment decision and preference ordering. The focus of investment failure has been on the investors irrational decision without questioning the rationality of information, how presented and communicated by management of the firm to the prospective investor. The information presented should be rational and meet all standard requirements in terms of generally accepted accounting standards, statutory and regulatory requirements and directives that may emanate from regulatory bodies and institutions. Communication of the information should be of concern in determining investment decisions. Communicating the information should be devoid of noise of any form. Available literature is concentrating on management interest and responsibility on accounting and presentation of financial statements to stakeholders with some short comings. Such limitations includes;communicating information as a linear and one-step model reacting to investors needs and not to create value; lack of market orientation in a proactive style to drive investors' value; not incorporating strategic planning in organisational learning and communication in presenting financial information.

The paper attempts to synthesize literature on presentation and communication of financial information, the possible noise that distort the rationality of information flow and the rationality of investment decision. Despite the volume of information used in investment decision, any selected amount from the right source,diligently and rationally prepared, presented and communicated rationally through the appropriate channel and medium devoid of noise, the resulting investment decision should be rational and appropriate. The paper covers; factors that determine rational financial information, communicating financial information, communication in complex situations, internallinkages and strategic alliance for communicationand conclusion and recommendations.

\section{A.Conceptual Framework}

Financial information may come from the financial statements and other professional, regulatory and expert sources which guide investment decisions. The model labelled Fig 1presentsfinancial statements as a form of market orientation that react to investors needs and not to derive customer value. It depicts communication as a linear one step communication system. This approachsatisfies just an information need to the user, but not creating value for the investor to appreciate the firm as owned. This limits holistic approach to communication with reactive market orientation and proactive approach soliciting feed back in investment decision for efficiency. The second model, Fig 
2 is presented to capture the holistic approach addressing the issues ofnoise in theinternal process, factoring quality of personnel, content abuse, standard assumptions and other ambiguities and distortions in the system. Approaching financial information communication with holistic view of physical and cognitive processes ensures that the communication is not a failure, but rather signifies that different cultural, intellectual and social differences lead to different precondition for interpretations and contextual understanding (

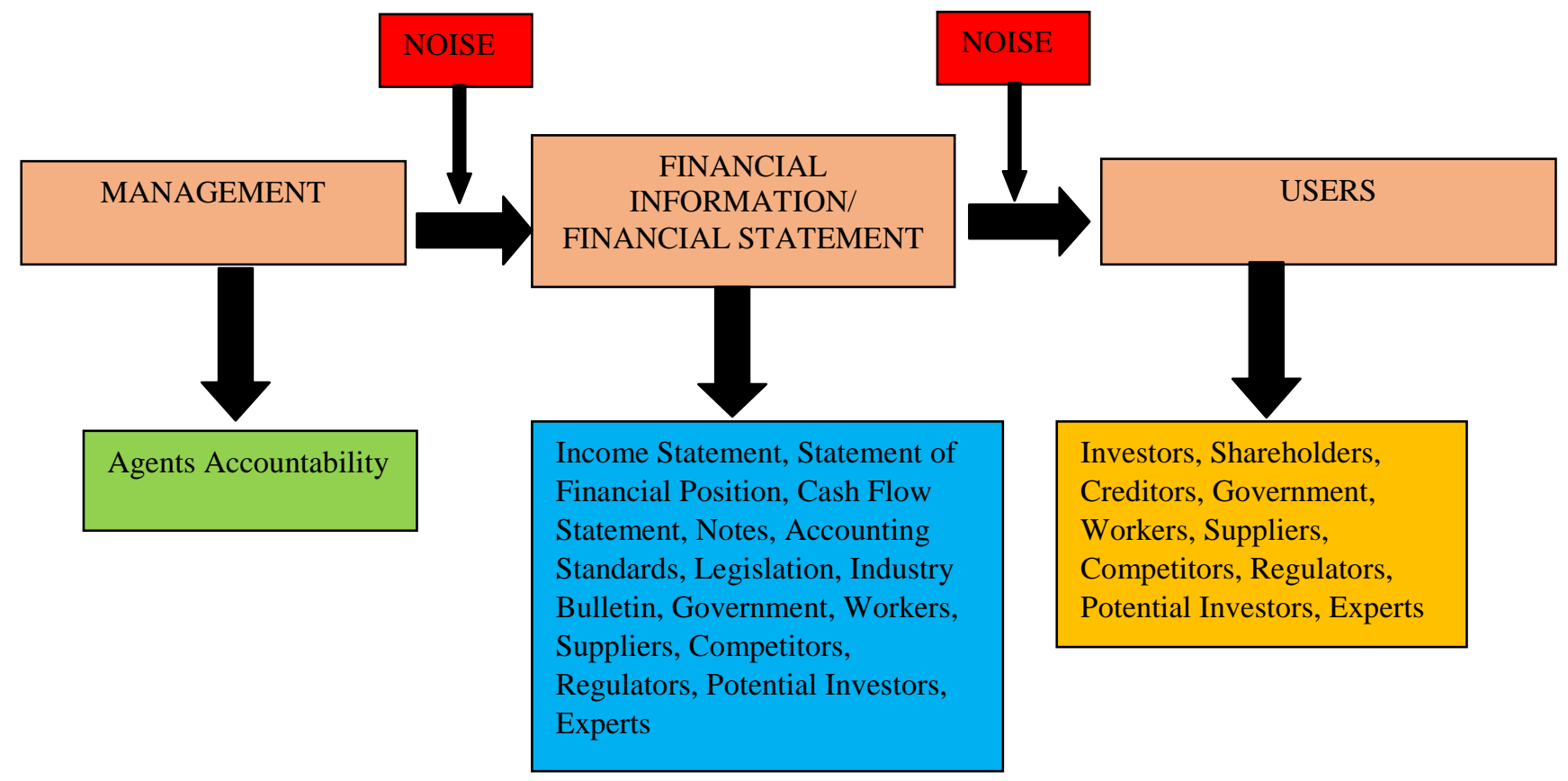

Fig 1. A Linear and a One-Step Model of Communication

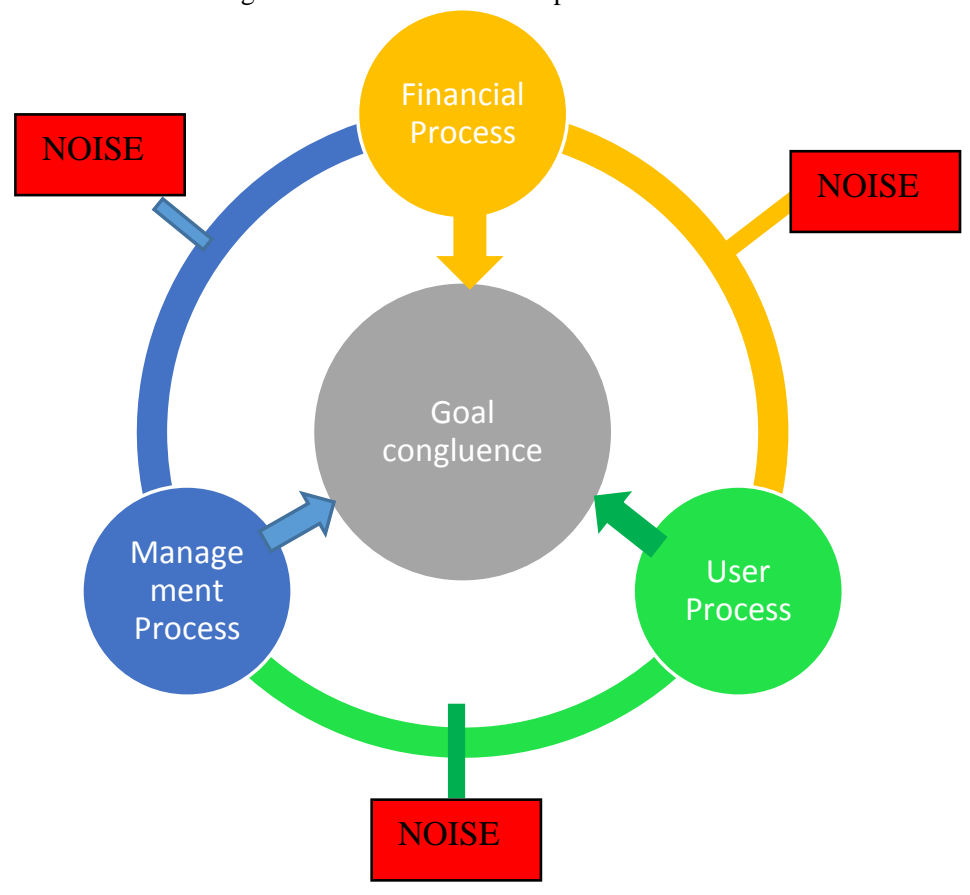

Fig 2. Proactive Market Orientation Strategic Presentation and Communication of Information 


\section{II: RATIONAL FINANCIAL INFORMATION}

The section addresses financial information and how it is presented to meet the needs of the investor. It considers the standard of financial information to be presented, the medium to be used to communicate the information, factors that can affect the rationality of information to be communicated and factors to consider for efficient communication of financial information.Investors depend on financial information,which should be relevant, in making an informed rational investment decision. Financial information may come from the financial statements which should guide most investment decision (Shaheen, 2010; Abdulkadir, Abubakar\&Danrim, 2016; Puspitaningtyas,). Financial information evidence the existenceof facts and assertions madeby management,as stewards, in the financial statements to fulfil their responsibility to the owners (Millichamp\& Taylor, 2008; Messier Jr., 2000; Whittington \& Pany, 2004; Abdulkadir, Abubakar\&Danrim (2016). The information representingthe financial state of the firm should be relevant, adequate, valid and appropriate (Millichamp\& Taylor, 2008; Messier Jr., 2000; Whittington \& Pany, 2004, Spitzier, Winter \& Meyer 2016; Abdulkadir, Abubakar\&Danrim, 2016) to meet the needs of potential investors to choose the investment asset preferred (Osuala, Ugwumbaand, Osuji, Okpara, 2012, Puspitaningtyas, (ud).

Relevantfinancial information should translate well to the assertions made and objectives underlying the decision (Whittington \& Pany, 2004) (Messier Jr., 2000; Shaheen, 2010; Osuala, Ugwumbaand, Osuji, Okpara, 2012; Obeng, up). The financial statement comprising; the statement of financial performance, statement of financial position, cash flow statement and disclosures made in the notes to the accounts,claims that the individual items are correctly described, show figures which are arithmetically correct or fairly estimated. To ensure some uniformity, continuity and consistency legislations are enacted by governments and standards formulated by professional accounting bodies and others to oversee corporate governance structures of firms, their operations and presentation of financial information to safeguard the assets of the entity and the interest of stakeholders. In Ghana for example there is the companies' code of 1963, Act 179 which provides the basis of corporate governance, accounting, presentation and auditing of financial statements and communication of financial information to interested parties or stakeholders of the company. There are professional accounting bodies that regulate the financial operations and controls of corporate entities. There is the International Federation of Accountants (IFAC) that is the umbrella of major national accounting bodies that put together accounting standards to regulate the accounting and financial statement and information preparation, auditing and presentation. When these principles are adhered to, then one should expect that the information provided should be rational enough to be relied upon for investment decisions. The information is gathered, generated and created through the internal management information systems of the business and normally managed by its own staff. The information is of interest to varying stakeholders who may need it for different and specific objectives and in different environments and cultures. The financial statement embodying the financial information, as audited is presented to the shareholders and other institutional and regulatory bodies; the Stock Exchange, Securities and Exchange Commission, the Registrar General and Central Bank through post and published in any other media acceptable by law.

Making the financial information or service available to the users is in itself marketing and communicating the financial information should have a marketing drive. Marketing as process of planning and executing the conception, pricing, promotion and distribution of a product, creates and exchange value and satisfy individual and organisational objectives (De Pelsmackeret al., 2001 in Holm, 2006). It should be present in communicating financial information. Taking the case of UT, Capital Banks and others in Ghana which were liquidated under the authority of the Bank of Ghanain 2017 and 2018, one may ask what transpired between the stakeholders in terms of communication before the crisis and demise of the banks. The UT Bank was listed on the Ghana Stock Exchange but yet could not raise enough equity funds to solve its solvency and liquidity problems. Leaving the stakeholders to operate on their own and independently could not achieve any collaboration and synergy in communication to benefit investors in their investment decision. The understanding and interpretation of the information by the different stakeholders can affect and influence their decision making and concerns about the firm. When the financial information is presented as a linear one step model it assumes satisfying just an information need to the user, the investor, but not creating value 
for the investor to appreciate the firm as owned. This limits holistic approach to communication with market orientation and proactive approach soliciting feed back in investment decision for efficiency.

\section{III:COMMUNICATING FINANCIAL INFORMATION- A LINEAR ONE-STEP MODEL}

Normally communication is seen as a process by which individuals share meaning (Holm, 2006). It is a transactional process between two or more parties to exchange meaning through the intentional use of symbols (Engel et al., 1994). A deliberate effort is made to bring about a response, and the participants are all involved in a symbolic interaction in which words, pictures and other stimuli are used to convey thoughts (Blythe, 2000 in Holm). Each participant must fully understand the meaning of the other's communication, or a counterproductive dialogue can ensue, or no dialogue is madel. Only through knowledge and understanding of the communication process are the actors likely to achieve their objectives of influencing attitudes, knowledge and behaviour with the aim of persuading, which is one of the most prominent reasons why organisations need to communicate (Fill, 1999).

From these principles communication is conveying meaning, it is transactional between parties which suggest they know themselves and have some existing agreed terms and conditions with selected words and symbols and work to achieve specific stated objectives. This amplifies a reactive style marketing communication enforcing rules (Smallman\& Weir 1999) and anything outside this create noise or counterproductive. As observed by (Bill Quirke, 1996) managers see communication as soft and separate and an event not a process.

On the business arena and for that matter in investment decisions, communicating information cannot be as simple as per these principles. To go by this a lot of noise, biases and distortions should be expected.Far from just being about the ability to give compelling presentations, communication competence is about recognising a conversation as a dialogue, and taking responsibility for the other person's communication effectiveness, (Richard J. Varey, 1996). Communication in business and on financial information involves many persons, different objectives, intentions and transactions creating different relationships. Without serious efforts goal congruence in the different relations would be difficult to achieve. Business financial information presented in financial statements are developed on the basis of assumptions, conventions and concepts that may convey more than the ordinary words, pictures and symbols to the user. Figures and words cannot be interpreted simply on their face values. The information communicated will be picked by different category of persons with different understanding, for different objectives, different transactions in different relations.

Communication built upon the three different systems - sound, image and the written word and consisting of five parts as an information source, a transmitter which operates on the message to produce a signal channel, the receiver and the destination cannot therefore fit easily in financial information communication. Literally it has been confined and assigned as a linear and a one-step model (Holm, 2006).Based on this one model approach business financial information has been presented and communicated with monocrotic focus for time and event (Quirke, 1996) with the investors' intensions and cognitive psychology in decision processes un-manifested. The linearity of communication limiting cognitive behavioural processes obscures the quality of the linkages between the various elements in the process (Varey, 1996) that determine whether the communication will be successful (Fill, 1999 in Holm, 2002). Quirke (1996) wrote on some behaviour of managers where they see communication as equal to information, production line, telling the troops, hierarchical, and megaphone mentalities suggesting how managers rubbish the importance of communication in managing the organization.

Approaching financial information communication with holistic view of physical and cognitive processes ensures that the communication is not a failure, but rather signifies that different cultural, intellectual and social differences lead to different precondition for interpretations and contextual understanding (Holm, 2002). Management of corporate business institutions should be directing attention to marketing strategies in communicating financial information that is proactive in orientation than being reactive to investors needs. Where the informationcommunicated is to react only to investors needs then it tends to satisfy a linear and a one-step model in which case communication becomes a strait jacket on the investors with no room to exercise any cognitive function in the decision making process. As observed 
by (Varey, 1996) communication is not just efficient talking, writing, listening and reading - nor is it merely an information transfer mechanism - there is also a cognitive or thinking component and an affective experience element. As a linear model it also creates a distinction between physical data handling and cognitive and psychological data processes (Obeng, up)in investment decision making which is not acceptable.

There cannot be decision without data processing and data is processed for decision only when committed to the mind to produce alternate actions to make a choice.Obeng (up) posited investment decision as a process of data collection processes and cognitive behaviour processes. The data collection phase has hard processing that identifies and recognizes the global sources and type of information to form a population for the decision making. The cognitive and soft processing selectsthe relevant information from the global or population data that meets the needs and interest of the decision maker or investor. There is the investment decision process ofdevelopment of alternative cognitive models with different outcomes and the cognitive behaviour to select the best alternative influenced by the understanding, interpretation of possible outcomes from the information analyzed.To view financial information communication as a linear and a one-step modelcreates a disjoint in the communication process and becomes a reactive to specific investors needs.To achieve proactive market orientation and holistic approach in communicating financial information there cannot be separate platforms for physical handling of information and cognitive and psychological processing of information in investment decision making. In this regard communicating financial information to the stakeholders as separate independent bodies with no linkages and collaboration is a disaster in investment decision.

\section{A.Management and Control of Communication of Financial Information}

Communication of information to users should be well managed and controlled to achieve desired objectives. Management and control of communication sets out how to measure the amount of information; how to measure the capacity of a communication channel; the rate at which a channel can convey information when the coding process is as efficient as possible; the general characteristics of "noise" in the system, and the means of minimizing or eliminating their negative effects (Holm, 2006).With the linear one-step model there is simple and specific approach to quantify the elements for the management and control of information in communication.For communication of financial information to achieve the desired objective of quality of the linkages between the various elements of different cultural, intellectual and social differences (Varey, 1996;Holm, 2006) leading to different precondition for interpretations and contextual understanding,attention should also be given to the management and control of communication.

The management and control of communication of financial information cannot anticipate rigorous adherence to such measuring principles. There should be some flexibility in measuring the amount of information; the capacity of a communication channel and the generality of the information processing in decision making on the part of the investor. In selection of financial information for processingand decision making, communication cannot be a mechanistic tool, which, like a water tap, can be turned on or off at the will of the individual 'communication initiator' or manager (Varey, 1996). Theinvestor considers cost and benefits relation and the relevance of the information to his course and not just the quantum of data at which a channel can convey information. This flexibility makes coding process as efficient as possible in contextual manner and limits the general characteristics of "noise" (Holm, 2006). In complex investment decision, communicating financial information as separate need to the varying stakeholders will distort the investment decision. Interpretation of the information by each independent body adhering to any strict measuring principles may be influenced by their culture and other dispositions. Information that may filter out from these bodies as distorted by their understanding in itself creates biases and noise in the investment decision process.

\section{IV: COMMUNICATION IN COMPLEX DECISIONS}

Investment decision making is tricky activity that needs conscientious effort to achieve a desired objective. The business environment has become very complex Drucker (1980) and Peters (1994) McClements and Smallman, 
1998;Smallman\&Weir,1999) because of competition and developments in information and communication technology. Communicating financial information to potential investors to make informed decision should be addressed in holistic approach (Smallman, 1996) with management taking centre stage.Financial information communication driven by market orientation proactively (Smallman, 1996) is advocated to improve investment decision making to achieve better outcome in returns.Strategic proactivenes as observed by (Atuahene-Gimaet al., 2005 in Hughes, Morgan\&Kouropalatis, 2008Smallman, 1996)is important keys to successful market orientation and enhanced performance. Research efforts on the relationship between market orientation and business performance has shown some positive relationship (Narver and Slater, 1990; Jaworski and Kohli, 1993; Slater and Narver, 1994a; Atuahene-Gima, 1995, 1996; Han et al., 1998; Hurley and Hult, 1998; Matsuno and Mentzer, 2000; Hult and Ketchen, 2001 as cited in Hughes, Morgan\&Kouropalatis, 2008).It is important for the business to know the environment in which it is operating to direct and achieve its objectives appropriately and strategically. Strategic proactivenes, according to (Hughes, Morgan\&Kouropalatis, 2008) impels continuous search for new opportunities and initiating innovative projects and programmes to capitalize on such opportunities (Mintzberg, 1973; Covin and Slevin, 1989; Miller, 1987). Smallman and Weir (1999) posited that strategic proactivenes rest on three key activities; monitoring, forecasting and organizational learning. To them monitoring requires continuous data collection and analysis of each aspects of concern, forecasting encompassing probability theory and actuarial models, and proven qualitative techniques that enable prediction of likely risk scenarios example scenario planning, Delphi technique (Wright and Ayton, 1987; Makridis and Wheelwright, 1989). In the case of organizational learning itis a powerful tool that enables all organizations to learn from past experiences and errors of themselves (Pedler et al., 1991; Senge, 1990). Knowledge about the environment should encompass all stakeholders and interested parties. Market orientation in communicating financial information should encourage organizational learning in processing information acquisition, dissemination and utilization, the encoding and retrieval of memory (Hughes, Morgan\&Kouropalatis, 2008). To know encourages research and learning to limit the incidence of speculation and other cognitive and psychological biases and distortions. As observed by (Hughes, Morgan\&Kouropalatis, 2008) propensity to strategize proactively requires firms to constantly scan for, disseminate, and apply timely market intelligence to decision-making processes.

Organizational learning enhances organizational forward-looking abilities and reduces the "frequency and magnitude of major shocks" (Day, 1994a, b; Sinkula, 1994 in Hughes, Morgan\&Kouropalatis, 2008).There is a duality of purpose in marketing oriented communication whereby in the process of caring for the customer or investor needs to satisfy them, the firm also brings to fore its own behaviours and cultures into perspective in the value chain (Homburg and Pflesser, 2000).The behavioural perspective of market orientation examines the organizational activities that are related to the generation, dissemination of and responsiveness to market intelligence (Kohli and Jaworski, 1990). The cultural perspective focuses on organizational norms and values that encourage behaviours that are consistent with market orientation (Narver and Slater, 1990; Deshpande et al., 1993).In the proactive model as observed by (Smallman\& Weir, 1999) there are two critical criteria that must be managed and fully accounted for; culture and communications.Smallman\& Weir, (1999);Thompson et al. (1990) who explored the risk preferences of different life styles (based on Douglas' (1992) grid-group typology postulated four types of cultural behaviour; individualists, eqalitarians, hierarchists and fatalist.

Individualists are bound neither by group incorporation nor prescribed roles. They regard risk as an opportunity.

Egalitarians operate within strong group boundaries with minimal prescriptions. Egalitarians attempt to shore up their way of life and discomfort rival ways.

Hierarchists are constrained by strong group boundaries and binding prescriptions. Based on "expert decisions" they are happy to set acceptable risks at high levels.

Fatalists must live up to binding prescriptions but are denied access to group membership. Hence, they do not 
knowingly take risks.

Thompson et al. (1990) observed a network in which risks are exchanged between the various ways of life. Each way of life will deal with the risks that its lifestyle acknowledges, ignoring the others and leaving them to be addressed by others.Addressing communication as the other aspect of the proactive model (Smallman and Weir, 1999) observed that most writing on systems failure contains a ritual reference to the importance of communication factors. However, the scheme is seldom developed in detail. Also, some contemporary treatments neglect communication entirely. To them the concept of communication provides a plausible basis for integrating the engineering and cultural theory approaches to risk. Smallman and Weir (1999) further indicted Communication as part of the "taken for granted" aspects of organizational life.However, as cultural theory and conventional sociology alike demonstrate, it should notberoblematic (van Krogh and Robb, 1995).Smallman and Weir, (1999) stressed that communication in complex organizations is an "achieved process". It has to be worked at and continually reviewed in order that its importance is not neglected.

Organisation does not exist on its own as an independent entity operating in isolation. The organisation has different divisions and functions that should work together as a team to contribute and share information in the context of the organizations objectives. The organization works and relate to other entities in the industry in which it is working in the economic environment where they link other institution of interest either by law or of specific and specialized interest. All these persons have their cultures and other dispositions that may influence the way they receive and interpret information in making decisions which decision may go a long way to affect the entity.The predominant view is that market orientation is positively related to business performance (Jaworski and Kohli, 1993; Slater and Narver, 1994a). In terms of the customer related benefits, market orientation has been found to enhance customer satisfaction and loyalty because market-oriented firms are well positioned to anticipate customer needs and to offer goods and services to satisfy those needs (Slater and Narver, 1994b).

To limit the incidence of biases and distortions in communicating information to interest groups and stakeholders the organization should adopt a proactive strategy in market orientation that monitors, forecasts and approve of organizational learning into the different cultures. The organization should be generous enough with strategic proactivenes in market orientation to be successful and enhanced performance. The behavioural perspective of market orientation facilitates generation, dissemination of and responsiveness to market intelligence and communication with investors with this background assures rational investment decision.

\section{V: INTERNAL LINKAGES AND STRATEGIC ALLIANCE FOR COMMUNICATION EFFICIENCY AND EFFECTIVENESS}

Communication of financial information fathomed in market orientation and in proactive strategy can lead to business performance and orchestrate good investment decision. This can be done by considering the internal communication processes and linkages with the information needs of external users in a holistic approach of information. The proactive strategy should work to attenuate factors that combine to increase the likelihood of a risk (investment failure/risk) developing into a hazardous event (Smallman\&Weir, 1996). This is collaboration risk management (Hood, 1996, pp. 214-6 in Smallman\& Weir). The internal communication function involves different sections or departments and personalities occupying different positions. The personalities in this case may have different philosophies and cultures that confront the organizations own philosophies and cultures. The external users also have their interest and objectives that influence them to invest in the firm and they do this by considering their cultures and other dispositions latent to their investment decision. It behoves on management to conduct fair assessment of the internal communication structure, quality of personnel, information systems, channels and flow of information and it works in consonance of the needs of external users to avoid any crises. The users, particularly investors' information needs and their capacity to process, understand and interpret information for investment decision to achieve their goal should be the driving force to direct the internal management information system.

The alliance within the organization and with the focus on users in a proactive strategy would avoid investment crisis. This will necessitate communication audits to enable managers to gather useful information about the quality of their organisation's internal communication system, and to propose suggestions for improvement (Brooks et al., 1979 in Lloyd\&Varey, (2003). If they are undertaken periodically, managers are kept fully informed of the state of the organisation's health and are forewarned of likely future problems (Sincoffet al., 1976). In the absence of good internal communication structure, assets and channel, the exposure of the system being a liability will be greater 
(Lloyd\&Varey, (2003).In communication audits (van Riel, 1995); an inventory of existing processes, activities, and artefacts of communication is compiled, to evaluate their consistency and impact. In addition to this human element of a communication audit is necessaryin assessing employees' feelings about the organisation (Argenti, 1998). Such staff attitude surveys assist with designing the right organisation structure (Lloyd\&Varey, (2003). The internal communication dynamics and system that handles management information to flow as directed in compliance with management strategic plan impacts on the investment decision. The firmis susceptible to crisis when the internal information and communication fails to deliver. In crises, the transmission of data is usually far more rapid and spasmodic. Hence, the actors will tend to process information more erratically and on an irregular basis through mainly ad hoc structures, since formal structures often degenerate rapidly in conditions of crisis(Lloyd\&Varey, (2003). Hughes, Morgan\&Kouropalatis, (2008) established in their studies that market orientation provides a firm with market-sensing and customer linking capabilities that lead to superior organizational performance when coupled with a propensity to act proactively upon the disseminated knowledge and information. Studies ( Hughes, Morgan\&Kouropalatis, 2008; Becker and Homburg, 1999)) has indeed shown that there is a positive relationship between market orientation and business performance when that relationship is moderated by strategic planning capabilities. In their work, "Factors affecting internal communication in a strategic alliance project", Corporate Communications (Heather L.E. Lloyd, Richard J. Varey, 2003)considered how to integrate organisations with differing cultures, values and processes into a fluid, productive and non-adversarial system of working.

This work can be replicatedto integrate individuals with different cultures and values working in an organization to achieve success in communication within and outside the organisation. Lloyd\&Varey, (2003) postulate that, the concept of communication provides a plausible basis for integrating the engineering and cultural theory approaches to risk. In accepting the challenge of ensuring the successful strategic alliance whilst still focusing on their individual work schedule/project delivery, workerscan foster good working relationships and camaraderie to facilitate continuous improvement in communications. Lloyd\&Varey, (2003) found that the main causes of systematic distortion of communication were personality clashes and internal meddling. They express the fear that, if people refuse to "park their baggage" from previous situations, a serious, perhaps irreparable division of cultures may result. This could adversely affect communications through reduced staff co-operation and motivation, as they may ultimately leave the organisation. Lloyd\&Varey, (2003) finally agreed that alliance project teams evidently saw free-flowing, integrated, bi-directional, and communication as fundamental to the project's success. In the internal communication of management information individual members of the organization through strategic alliance integrate free-flow of information and also between the firm and external stakeholder for mutual understanding, cooperation and bi-directional communication to achieve success in its performance and goal congruence. A case in hand about challenges facing corporate institutions on communication is the liquidation of UT Bank by the Bank of Ghana, the regulator as one institution that relied on available information at its disposal to arrive that decision. Before that the bank was adjudged the bank of the year which decision was also based on available information at disposal of the awarding institution. It could be deduced from this development that the information was communicated in a linear one-step model. Secondly management and control of communication was, in strict adherence to stereo type measurement of the amount of information; the capacity of a communication channel; the rate at which a channel can convey information when the coding process is as efficient as possible; the general characteristics of "noise" in the system, and the means of minimizing or eliminating their negative effects (Holm, 2006).Investors who relied on the award to the bank as the bank of the year have suffered a fail investment. Strategic proactivenes in market orientation, internal linkages and strategic alliance for communication should be of importance to corporate institutions in generating and communicating information which is to be relied on by investors in making their investment decisions to avoid failure

\section{VI: CONCLUSION AND RECOMMENDATION}

Information plays vital role in every human endeavour and in the business world financial information is relied on by many stakeholders including investors. The information presented in the financial statement should be rational and meet all standard requirements in terms of generally accepted accounting standards, statutory and regulatory requirements and directives that may emanate from regulatory bodies and institutions. Communication of the information should be of concern in determining investment decisions. The management should put in place the right systems, standards and policies (Kumar and Goyal, 2016; Byrne, Jackson, Lee, 2013) that ensure rational (Lizieri, 2009;Byrne, Jackson, Lee, 2013) generation of information and how presented and communicated to all stakeholders 
for their investment decision. Making the financial information or service available to the users is in itself marketing and communicating the financial information should have a marketing drive. Communicating financial information to potential investors to make informed decision should be addressed in holistic approach (Smallman, 1996) with management taking centre stage. Communicating financial information should not be seen as conveying meaning, or as transactional between parties which suggest they know themselves and have some existing agreed terms and conditions with selected words and symbols to work and achieve specific stated objectives. It need not be a reactive style marketing communication enforcing rules (Smallman\& Weir 1999) that open the flood gates for biases and create noise or counterproductive. In the process managers should be focusing on proactive market orientation in their communication of financial information and not as an event but as a process as observed by (Bill Quirke, 1996). A proactive strategy in market orientation monitors, forecasts and approve of organizational learning into different cultures. In a behavioural sense market orientation facilitates generation, dissemination of and responsiveness to market intelligence and communication with investors, in this regard, assured of rational investment decision. The proactive strategy should work to attenuate factors that combine to increase the likelihood of risk of investment failure developing into a hazardous event (Smallman\&Weir, 1996).

Management should take up the responsibility of providing the right and rational information and develop strategic alliance that integrates individuals with different cultures and values working in an organization to achieve success in communication within and outside the organisation. As observed by (Lloyd\&Varey, 2003) the concept of communication provides a plausible basis for integrating the engineering and cultural theory approaches to risk. In accepting the challenge of ensuring the successful strategic alliance whilst still focusing on their individual work schedule, workers can foster good working relationships to facilitate continuous improvement in communications. In effect they should be responsible for the provision of the right information and communicate same in proactive market orientation creating alliances within and outside the organisation that investment decisions emanating there from achieve the objective required. Failure of theseinvestors will respond by given the firm its deserved capital structure and not as management requires whichshould be blamed on management not the investor.

\section{Recommendations}

Communication of financial information should not be seen as a linear one-step model conveying meaning, or as transactional between independent parties with distinct independent objectives to be achieved.

Communication of financial information should be taken as serious business with market orientation that proactively strategizesincollaborating intent and linkages with individual members of the organization within and with other stakeholders outside the organization.

The proactive market orientation should be congenial for monitoring continuously data collection and analysis of each aspects of concern. It should see to it that the basis and methodology for data collection and analysis are consistent with current and prevailing trend in the economic environment and other challenges. There should be organizational learning that enables the organization to learn from past experiences and errors of themselves. Proactive strategy should spur forecasting encompassing probability theory and actuarial models, and proven qualitative techniques that enable prediction of likely risk scenarios.

Investors should not rely on one source of information and communication but strife to collaborate with other sources and interest groups to ensure communication of financial information to them is embedded with common stakes to achieve goal congruence.

Management should be responsible for any investment failure emanating from investors relying on information from management.

\section{ACKNOWLEDGEMENT}

I may want to express my gratitude to the following persons for their immense support and contributions in various ways in my research work; 
International Journal of Science and Management Studies (IJSMS)

Volume: 2 Issue: 4
July to August 2019
E-ISSN: 2581-5946

www.ijsmsjournal.org

Dr.DadsonAwunyoVitor, of Kwame Nkrumah University of Science and Technology, Mr. Alfred Abasa Morrison and Mr. Emmanuel Kofi Owusu all of University of Education, Winneba, College of Technology Education Kumasi

\section{REFERENCES}

[1] M. Abdulkadir,H. Abubakar, andL. M. Danrim, L. M. The effect of financial reporting on investment decision making by banks in Nigeria,International Journal of Research in Finance and Marketing, Vol. 6 issue 4 (2016)

[2] P. A. Argenti, Corporate Communication, 2nd ed., Irwin McGraw-Hill, Boston, MA, p. 170. (1998), [Google Scholar]

[3] K. Atuahene-Gima, "An exploratory analysis of the impact of market orientation on new product performance: a contingency approach", Journal of Product Innovation Management, Vol. 12 No. 4, pp. 275-93. (1995), [Crossref], [ISI], [Google Scholar][Infotrieve]

[4] K. Atuahene-Gima, "Market orientation and innovation", Journal of Business Research, Vol. 35 No. 2, pp. 93-103. (1996), [Crossref],[ISI], [Google Scholar][Infotrieve]

[5] K. AtuaheneGima, S. F. Slater and E. M. Olson, "The contingent value of responsive and proactive market orientations for new product program performance", Journal of Product Innovation Management, Vol. 22 No. 6, pp. 464-82. (2005), [Crossref], [ISI], [Google Scholar][Infotrieve]

[6] N. Baberis, andR.Thaler, R, A survey of behavioural finance handbook of the Economics of Finance Elsevier Science B.V (2003)

[7] Z. Bodie, A. Kane, \&A. Marcus, Investment ( $5^{\text {th }}$ ed.), Boston, McGraw-Hill Irwin (2002)

[8] P. Byrne, C. JacksonandS. Lee, "Bias or rationality"? The case of UK commercial real estate investment", Journal of European Real Estate Research, Vol. 6 Issue: 1, pp.6-33, (2013)https://doi.org/10.1108/17539261311312960C (2008) (Copenhagen Business School, Copenhagen, Denmark)

[9] J. G. Covin, and D. P. Slevin, Strategic management of small firms in hostile and benign environments, Strategic Management Journal, Vol. 10 No. 1, pp. 75-87. (1989), [Crossref], [ISI], [Google Scholar][Infotrieve]

[10] G. S. Day, ,Continuous learning about markets, California Management Review, Vol. 36, pp. 9-31. (1994a)[Crossref], [ISI], [Google Scholar]

[11] G. S. Day “The capabilities of market driven organizations”, Journal of Marketing, Vol. 37, p. 52. (1994b), [Google Scholar]

[12] R. Deshpande, J. U. Farley, and F. E. Webster Jr "Corporate culture, customer orientation, and innovativeness", Journal of Marketing, Vol.57 No. 1, pp. 23-37. (1993),[Crossref], [ISI], [Google Scholar][Infotrieve]

[13] G. Dyer, Advertising as Communication, Routledge, London ,(1982). [Google Scholar]

[14] C. B. Eaton, F. D. Eaton,andW. D. Allen, Micro Economics Theory with Applications. Toronto, Canada: Pearson Prentice Hall (2005).

[15] J.F Engel, M.R Warshaw,.andT. Kinnear, Promotional Strategy: Managing the Marketing Communications Process, 8th ed., Irwin, Burr Ridge, IL. (1994),[Google Scholar]

[16] C. Fill, Marketing Communications, Context, Contents and Strategies, 2nd ed., Prentice-Hall, Englewood Cliffs, NJ. (1999), [Google Scholar]

[17] M.E. González, G., Quesada, R.Mueller, and C.A. Mora-Monge, "QFD strategy house: an innovative tool for linking marketing and manufacturing strategies", Marketing Intelligence \& Planning, Vol. 22 No. 3, pp. 335-48. (2004), [Link], [Google Scholar][Infotrieve]

[18] J.K., Han, N. Kim, and R.K. Srivastava, "Market orientation and organizational performance: is innovation the missing link?"Journal of Marketing, Vol. 62 No. 4, pp. 30-45. (1998), [Crossref], [ISI], [Google Scholar][Infotrieve]

[19] L.E. Heather Lloyd, andJ. Richard Varey, "Factors affecting internal communication in a strategic alliance project", Corporate Communications: An International Journal, Vol. 8 Issue: 3, pp.197-207, (2003) https://doi.org/10.1108/13563280310487658

[20] T. Hernes, and T. Bakken, "Implications of self-reference: NiklasLuthmann'sautopoiesis and organization theory", Organization Studies, Vol. 24, pp. 1511-35. (2003), [Crossref], [Google Scholar]

[21] O. Holm, StrategiskMarknadskommunikation - teorierochmetoder (Strategic Marketing Communications - Theories and Methods), Liber, Malmö. (2002), [Google Scholar]

[22] Holm, (2006), "Integrated marketing communications: from tactics to strategy", Corporate Communications: An International Journal, Vol. 11 No. 1, pp. 23-33. [Link], [Google Scholar][Infotrieve] 
International Journal of Science and Management Studies (IJSMS)

Volume: 2 Issue: 4
July to August 2019
E-ISSN: 2581-5946

\section{www.ijsmsjournal.org}

[23] O. Holm, "Communication processes in critical systems: dialogues concerning communications", Marketing Intelligence \& Planning, Vol. 24 Issue: 5, pp.493-504, (2006)https://doi.org/10.1108/02634500610682881

[24] C. Homburg, and C. Pflesser, "A multiple-layer model of market-oriented organizational culture: measurement issues and performance outcomes", Journal of Marketing Research, Vol. 37 No. 4, pp. 449-62. (2000), [Crossref], [ISI], [Google Scholar][Infotrieve]

[25] C.C. Hood, "Where extremes meet: 'SPRAT' versus 'SHARK' in public risk management”, in Hood, C.C. and Jones, D.K.C. (Eds), Accident and Design. Contemporary Debates in Risk Management, UCL Press, London, pp. 205-27. (1996), [Google Scholar]

[26] C. Lizieri, Towers of Capital: Office Markets and International Financial Services, Wiley-Blackwell, Chichester. (2009),[Google Scholar]

[27] P. E. Morgan, andY. Kouropalatis, "Market knowledge diffusion and business performance", European Journal of Marketing, Vol. 42 Issue: 11/12, pp.1372-1395, (2008) https://doi.org/10.1108/03090560810903718

[28] A, Jagongo, and V. S. Mutswenje, A survey of the factors influencing investment decision: the case of individual investors at NSE; International Journal of Humanities and Social Sciences Vol. 4 No 4 (pp. 92-102) , (2014)..

[29] D. Kahneman, Attention and Effort, Prentice-Hall, Englewood Cliffs, NJ. (1973),[Google Scholar]

[30] G. Kong, and D. Kong, "Institutional investors' trading in speculation: evidence from China”, South African Journal of Economics, Vol. 83 No. 4, pp. 617-631. (2015), [Crossref], [Google Scholar][Infotrieve]

[31] J. Livanas, Empirical Analysis of Investor Utilities in Investment Choice; Institute of Actuaries of Australia; Risk and Capital Management Research Conference 2008, Sydney, Australia(2008);

[32] W. F. Messier, (Jr) Auditing and assurance services ( $\left.2^{\text {nd }}\right)$, Boston, McGraw Hill Irwin) (2000)

[33] G.A. Miller. "The magical number seven, plus or minus two: some limits on our capacity for processing information", Psychological Review, Vol. 63 No. 2, pp. 81-97. (1957), [Crossref], [Google Scholar][Infotrieve]

[34] A.H. Millichamp, andJ. R Taylor, Auditing ( $9^{\text {th }}$ ed.), London Cengage Learning EMEA (2008)

[35] Mohammad Tariqul Islam Khan, Siow-Hooi Tan, Lee-Lee Chong, "Information sources and investing decisions - a path modelling approach", Managerial Finance, Vol. 43 Issue: 8, pp.928-947, (2017) https://doi.org/10.1108/MF-08-2016-0232

[36] O. Musshoff, \&N. Hirschauer, "A behavioural economic analysis of bounded rationality in farm financing decisions: First empirical evidence", Agricultural Finance Review, Vol. 71 Issue: 1, pp.62-83, (2011) https://doi.org/10.1108/00021461111128165

[37] C. S. Myers, andA, B. Brealey, Principles of corporate finance, Boston, McGraw-Hill Irwin(2003):

[38] A. E., Osuela, , E. C., Ugwumbaan, J. J. Osuji, M. Okpara, Financial statements content and investment decision - a study of selected firms, JORIND (2012). Vol. (2), www.transcampus.org/journals.

[39] Z. Puspitaningtyas, (ud.). How accounting information is useful for investors, www.academia.edu./237544. (350-354)

[40] B. Quirke, Putting communication on management's agendaReceived: 27th March, 1996 Synopsis Communication Consulting, 62-68, (1996)

[41] S. A., Ross, R. W., Westerfield, andJ. Jaffe, Corporate finance ( $6^{\text {th }}$ ed.), Boston, McGraw- Irwin (2002):

[42] Satish Kumar, Nisha Goyal, "Evidence on rationality and behavioural biases in investment decision making", Qualitative Research in Financial Markets, Vol. 8 Issue: 4, pp.270-287, (2016) https://doi.org/10.1108/QRFM-05-2016-0016

[43] D. Scharfstein, and J. Stein, "Herd behaviour and investment", American Economic Review, Vol. 80 No. 3, pp. 465-479. (1990), [Google Scholar][Infotrieve]

[44] Y. Shaheen, The perceived usefulness of information for investment decisions: Evidence from Palestine Security Exchange, Hebron University Research Journal Vol. (5) No. (2) pp (283 - 307) (2010).

[45] H. Shefrin "Beyond greed and fear", Harvard University Press, Boston (2000),

[46] R.J. Shiller Market Volatility, MIT Press, Cambridge, MA. (1989), [Google Scholar]

[47] A. Shleifer "Inefficient Markets", Oxford University Press. (2000),

[48] H. A. Simon, A behavioural model of rational choice, The Quarterly Journal of Economics, Vol. 69, Issue 1(1955),

(C) 2019, IJSMS

Page 78 
Volume: 2 Issue: 4

July to August 2019

www.ijsmsjournal.org

[49] M.Z., Sincoff, D.A.Williams, and C.E.T.Rohm, "Steps in performing a communication audit", paper presented at the meeting of the International Communication Association, Portland, May 1976, in Kreps, G.L. (1996), Organizational Communication, Theory and Practice, 2nd ed., Longman, New York, NY, p. 215. (1976), [Google Scholar]

[50] I.S. Slavin, Economics (6 $\left.6^{\text {th }} e d\right)$. New York: McGraw Hill Irwin. (2002).

[51] C. Smallman, "Challenging the orthodoxy in risk management", Safety Science, Vol. 22 Nos. 1-3, pp. 245-62. (1996), [Crossref], [ISI], [Google Scholar]

[52] C. Smallman, andD. Weir, "Communication and cultural distortion during crises", Disaster Prevention and Management: An International Journal, Vol. 8 Issue: 1, pp.33-41, (1999) https://doi.org/10.1108/09653569910258219

[53] C. Spitzier,H..Winter, \&J. Meyer,. Relevant and reliable information, Wilky online library, (2016) https://doi.org/10,1002/978119176657,ch06

[54] M., Thompson, E Ellis, and A. Wildavsky, Cultural Theory, Westview Press, Oxford. (1990), [Google Scholar]

[55] G. van Krogh, and J.Robb, Organizational Epistemology, Macmillan, London. (1995), [Google Scholar]

[56] C.B.M.van Riel, Principles of Corporate Communication, Prentice-Hall, Hemel Hempstead, Hertfordshire, p. 65. (1995), [Google Scholar]

[57] R. J Varey, Conscious corporate communication: A conceptual analysis Received (in revised form): 17th June, 1996 BNFL Corporate Communications Unit, The Management School, University of Salford, (1996)

[58] O. R., Whittington, andK. Pany, Principles of auditing and other assurance services (14 ${ }^{\text {th }}$ ed.), Boston, McGraw Hill Irwin (2004),

[59] S. A. Zahera, andR. Bansal, "Do investors exhibit behavioural biases in investment decision making? A systematic review", Qualitative Research in Financial Markets, Vol. 10 Issue: 2, pp.210-251, (2018) https://doi.org/10.1108/QRFM-04-2017-0028 